\title{
Conflux of interest. Revealing multiple value systems in socially motivated collaborative university based projects
}

\author{
Cristina Cerulli \\ Sheffield Hallam University, United Kingdom \\ c.cerulli@shu.ac.uk
}

\begin{abstract}
This paper discusses how collaborative and interdisciplinary socially-motivated projects and academic project-based research within the disciplines of architecture and design occupy a special territory where professional and social norms might be challenged and new types of relationships might be forged that question prevailing practices. After an initial section setting the context of the political economy of such projects, the second part of the paper reflects on the practice of these types of projects through the lens of specific projects carried out with external organisations ranging from relatively large networks of practice and research to a small, emerging community land trust. These reflections call for a new vocabulary to help articulate the value systems underpinning such projects in a way that bypasses the normative focus on competition and its corollary conflict of interest.
\end{abstract}

Keywords: professionalism, project-based research, collaborations, value systems, design pedagogy.

\section{To cite this article:}

Cerulli, C. (20I7). Conflux of interest. Revealing multiple value systems in socially motivated collaborative university based projects. The Journal of Public Space, 2(3), Special Issue, II-20, DOI: 10.5204/jps.v2i3. 108

This article has been peer-reviewed and accepted for publication in The Journal of Public Space. Please see the Editorial Policies under the 'About' section of the journal website for further information.

This work is licensed under a Creative Commons Attribution - Non Commercial 4.0 International License https://creativecommons.org/licenses/by-nc/4.0/ 


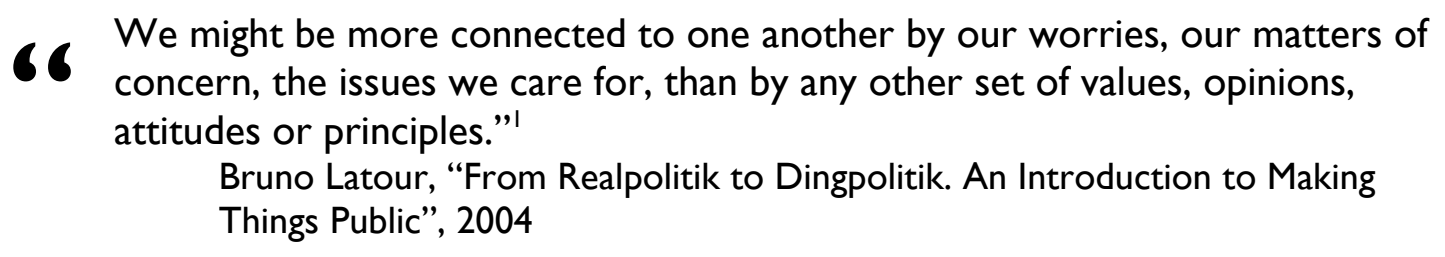

\section{Introduction}

This paper reflects on collaborative, interdisciplinary pedagogical practices between universities and external partners to set the ground for a theoretical framework to understand them in relation to mutually beneficial arrangements and value created through those collaborations.

Convergence of mutual interests is at odds with some disciplinary and professional stances, which are generally more equipped and attuned to deal with conflict of interest, and which can also be seen as a corollary of the competition paradigm underpinning a large part of professional practice, from tender processes to architectural competitions. Architectural professional codes of conduct, contracts and tender documents, for instance, regularly contain prompts to declare any potential conflict of interest that might affect participants' abilities to act 'professionally', that is to say, as service providers, privileging one value system, that of the client, over the ones of other parties.

\section{Blurring boundaries}

Collaborative and interdisciplinary projects have become part of the educational offer within many higher education architecture, built environment and design-based courses ${ }^{2}$ and reflect a drive towards social realism in architectural education. ${ }^{3}$ There are multiple models of pedagogical projects attempting to deal with the complexity of the "real" as well as with the practicalities of the "applied" and material, many of which are labelled as "live." These vary hugely in nature and scope and can be community-based, "design and build" and "interdisciplinary" or any combination of the three. ${ }^{4}$ Such projects usually involve a "negotiation of a brief, timescale, budget and product between an educational organisation and an external collaborator for their mutual benefit." ${ }^{5}$ Crucially they also need to be structured to facilitate learning that is aligned with programme specifications. ${ }^{6}$ Projects where university staff, students and third parties, external to universities, collaborate on shared endeavours, because of the powerful synergy between their often

\footnotetext{
${ }^{\prime}$ http://www.bruno-latour.fr/node/208.

2 Rachel Sara, "Learning from Life: Exploring the Potential of Live Projects in Higher Education," Journal for Education in the Built Environment 6, n. 2 (December 201 I): 8-25.

3 Tatjana Schneider, “Architecture, Education, and Cedric Price: Get a Grip, Future Architects.” The Metropolitan Laboratory I (20I6).

${ }^{4}$ Rachel Sara "Live Project Good Practice: A Guide for the Implementation of Live Projects." CEBE Briefing Guide Series 8 (2006): 1-7.

5 Jane Anderson and Colin Priest, "Developing an Inclusive Definition, Typological Analysis and Online Resource for Live Projects," in Architecture Live Projects. Pedagogy into Practice, ed. Harriet Harriss and Lynnette Widder (Abingdon: Routledge, 2014).

${ }^{6}$ Jane Anderson and Colin Priest, “About: Live Projects Network,” accessed October I, 2016 http://liveprojectsnetwork.org/about.
} 
quasi-professional nature and the critical and creative freedom still possible within university curricula, have great potential to be transformative both within and outside academia. Discussing the pedagogical model of "live project," Rachel Sara frames its privileged position of in-between the "binaries of theory and practice, university and community, designing and making, the head and the hand, and ideas about what it is to be a student, and what it is to be a professional" as transgression of boundaries. ${ }^{7}$ The host institution of such projects, the university, becomes a mediator - sometimes facilitating, sometime resisting, a blurring of the boundaries between lay and expert knowledges ${ }^{8}$ and designerly ways of knowing, " opening up possibilities to create new knowledges across divides, domains and agendas. It has been argued that an "engaged" approach to teaching can facilitate the emergence of dynamic forms of learning that go beyond subject-specific knowledge with deeper intellectual rigour, while also facilitating the development of citizenship attributes and employability skills. ${ }^{10}$

The active role that students take in shaping their own learning as well as the external contexts in which they operate, often induce "a heightened sense of vulnerability and uncertainty" that is at the same time "exhilarating and problematic." "Within the extended learning networks of participants and stakeholders created through collaborative and interdisciplinary projects, there is often a productive tension between "cohesiveness and divisiveness," 12 which is common in learning communities. ${ }^{13}$ This tension needs to be understood and embraced. Understanding the power relations in academic-based collaborative and interdisciplinary projects not only has bearings upon the politics of those projects and of the organisations involved, but also on the ethics of such projects. The ambiguous and multifaceted nature of the designer educator and their double design role in academic project-based research - as designer of pedagogies and designer of interventions - is key to shaping the power relations and the scope of projects. The academic/practitioner engaged in academic-based collaborative and interdisciplinary projects can be both strategist and tactician, creating and occupying spaces for engagement and participation. ${ }^{14}$

\footnotetext{
${ }^{7}$ Rachel Sara, 'Learning from Life - Exploring the Potential of Live Projects in Higher Education'. ${ }^{8}$ Jacqueline McIntosh, Philippe Campays, Maibritt Pedersen Zari, and Bruno Marques, "Education as Mediation: Blurring the Line Between Expert and Lay Knowledge," in Applied Collaborations, ed. Daniel K. Brown, Manfredo Manfredini, Peter McPherson, Annabel Pretty, Uwe Rieger, and Mark Southcombe, AASA 2015 International Conference Procveedings, Christchurch, New Zealand: 222-29.

${ }^{9}$ Nigel Cross, "Designerly Ways of Knowing: Design Discipline Versus Design Science." Design Issues 17, n. 3 (July 200 I): 49-55. doi: I0.I I62/07479360 I750357 I 96; “Designerly Ways of Knowing," Design Studies 3, no. 4 (1982): 22I-27.

${ }^{10}$ Julia Udall, David Forrest, and Katie Stewart, "Locating and Building Knowledges Outside of the Academy: Approaches to Engaged Teaching at the University of Sheffield," Teaching in Higher Education 20, n. 2 (February 2015): 158-70. doi:10.1080/135625I7.2014.966237.

"McIntosh, Campays, Pedersen Zari, and Marques, "Education as Mediation."

${ }^{12}$ Ibid.

${ }^{13}$ David Jaffee, "Learning Communities Can Be Cohesive and Divisive." Chronicle of Higher Education 9 (July 2004); Patricia A. James, Patrick L. Bruch, and Rashné R. Jehangir, "Ideas in Practice: Building Bridges in a Multicultural Learning Community," Journal of Developmental Education 29, n. 3 (Spring 2006): 10-12,14$15,18$.

${ }^{14}$ Michel de Certeau, The Practice of Everyday Life, trans. Steven Rendall (Berkeley; University of California Press, 1988); Yanki Lee and Jo-Anne Bichard, “'Teen-Scape': Designing Participations for the Design Excluded," in PDC '08: Proceedings of the Tenth Anniversary Conference on Participatory Design 2008 (Indianapolis: Indiana University, 2008), I28-137, http://dl.acm.org/citation.cfm?id=|795234.1795253;
} 


\section{Political economies of university based collaborative and interdisciplinary projects}

Projects where academic institutions work interdisciplinarily and collaboratively with external partners to achieve specific outcomes need to be understood as complex ecologies. In the context of increasingly neoliberal universities, where academic capitalism ${ }^{15}$ is becoming the norm, ${ }^{16}$ such projects have the potential to configure themselves as effective pockets of resistance, but they can also become instruments for validating and reinforcing the status quo, depending on how they are initiated, developed, framed and assessed.

Collaborative projects, especially those with an aim to achieve some social outcome within cities, are at odds with a neoliberal worldview, where individuals become isolated consumers at the mercy of the laws of supply and demand, ${ }^{17}$ undermining any idea of collective action to shape the way we live. In the context of capitalism, based on precarity of workforce and fragmentations of institutions, people are usually prevented from engaging in mutually supportive social relationships. ${ }^{18}$ Nevertheless, in reaction to this dominant worldview, a new conceptual landscape around issues of mutuality and commons is emerging, with a focus on mutual and community organisational structures and forms of ownership (including customary and common, community, co-operative and mutual, charitable), governance and economics. ${ }^{19}$ Other views of economics, ${ }^{20}$ including feminist approaches, ${ }^{21}$ prepared the ground for a stream of academic work concerned with diverse economies and explicitly choosing "to bring marginalized, hidden and alternative economic activities to light in order to make them more real and more credible as objects of policy and activism."22

\footnotetext{
Vincenzo D’Andrea and Maurizio Teli, “Teaching Participatory Design: A Participatory Approach,” in PDC 'I 0: Proceedings of the I I th Biennial Participatory Design Conference (New York: ACM Press, 2010), 223-226, doi:10.1 |45/190044I.1900486.

${ }^{15}$ Sheila Slaughter and Larry L. Leslie, Academic Capitalism: Politics, Policies, and the Entrepreneurial University (Baltimore: Johns Hopkins University Press, 1997), http://eric.ed.gov/?id=ED409816.

${ }^{16}$ Oili-Helena Ylijoki, "Entangled in Academic Capitalism? A Case-Study on Changing Ideals and Practices of University Research," Higher Education 45, n. 3 (April 2003): 307-35, doi:I0. I023/A:I 0226679237I5.

${ }_{17}$ BAVO, "Introduction," in Urban Politics Now, Re-Imagining Democracy in the Neoliberal City ed. BAVO (Rotterdam: NAI, 2007), 7.

${ }^{18}$ Richard Sennett, Together: The Rituals, Pleasures and Politics of Cooperation (London: Penguin, 2013): 279.

${ }^{19}$ Cristina Cerulli, "Mutually, Commonly," in TRANS LOCAL ACT: Cultural Practices Within and Across, ed.

Doina Petrescu, Constantin Petcou, and Nishat Awan (Paris: AAA/PEPRAV, 2010), 287-98, www.rhyzom.net.

${ }^{20}$ François Schneider, Giorgos Kallis, and Joan Martinez-Alier, "Crisis or Opportunity? Economic Degrowth for Social Equity and Ecological Sustainability. Introduction to This Special Issue," Journal of Cleaner Production 18, n. 6 (April 2010): 5II-I8. doi:10.1016/j.jclepro.2010.01.014; Elinor Ostrom, Governing the Commons: The Evolution of Institutions for Collective Action (Cambridge: Cambridge University Press, 1990); Marilyn Waring, If Women Counted: A New Feminist Economics (San Francisco: Harper \& Row, 1988); Ernst F.Schumacher, Small Is Beautiful: A Study of Economics as If People Mattered (London: Vintage, 1993); Valentin Cojanu, "GeorgescuRoegen's Entropic Model: A Methodological Appraisal,” International Journal of Social Economics 36, n. 3 (2009): 274-86; Nicholas Georgescu-Roegen, The Entropy Law and the Economic Process (Cambridge, MA: Harvard University Press, 197I).

${ }^{21}$ Marilyn Friedman, What Are Friends For?: Feminist Perspectives on Personal Relationships and Moral Theory (Ithaca: Cornell University Press, 1994).

${ }^{22}$ J. K. Gibson-Graham, “Diverse Economies: Performative Practices for 'Other Worlds,"” Progress in Human Geography 32, n. 5 (2008): 6I3-32. doi: I0.II77/0309/3250809082I.
} 
It is in this context that the collaborations between universities and third sector actors, as collective endeavours within the city, can be seen as spaces of resistance and, as educators and designers, we can put forward multiple strategies to develop enabling frameworks as well as support and care systems at a range of scales and in various realms. ${ }^{23}$ Interdisciplinary collaborations with other civic actors are the ideal locus in which such enabling frameworks can be prototyped, tested and, crucially, sustained. The privileged in-between and hybrid nature of these collaborative efforts is an ideal condition for experimentation, making them vehicles through which political positions can be enacted within university curricula. Setting up a project, designing the extent of mutual exchanges, the partnerships, the research questions, all imply political choices, but they are also all "normal," accepted, activities, core to the delivery of innovative and competitive academic programs and, for this reason, they are not scrutinised, hindered or filtered out. On the contrary, collaborative and interdisciplinary projects in which universities work with external stakeholders and actors are often promoted as flagship initiatives, since their aims and the methods appear aligned with those of the engaged civic university ${ }^{24}$ - an attempt to reconcile market pressures and ethical stances within universities. It could be argued that, because of their affinity with the objectives of the civic engaged university, collaborative projects with external partners are, potentially, an ideal place in which to resist and contest academic capitalism from within. This would also strongly characterise these projects as a particular form of Morrow's reconceptualisation activism, revealing values and potentials. ${ }^{25}$

Furthermore, in the contemporary university context, where "human resources" are increasingly squeezed through narratives of excellence and impact, such collaborative projects are one of the few situations where time formally accounted as "teaching" can be actually also allocated to practice-based research activities. A separate challenge is how to have those research activities recognised as valid and "worthwhile." Contrary to the stance that creative research should be a tautology rather than an oxymoron, ${ }^{26}$ designbased research is still marginalised within accepted academic research quality assessment frameworks. ${ }^{27}$

\section{Critically contributing to wider programs}

On-going wider collaborations between universities, civil society organisations and public bodies around specific research questions, cultural programmes or societal challenges have the potential to be an ideal environment in which to develop discrete, short term, student projects. Funding attached to those wider projects can be budgeted to allocate resources to support and enhance student projects, creating a multiplier effect so that relatively small additional resources (for travel, final outputs, dissemination, engagement activities etc.) can have impact on both the student learning experience and the wider

\footnotetext{
${ }^{23}$ Cristina Cerulli, "Abitare Insieme / Living Together."

${ }^{24}$ John Goddard, Reinventing the Civic University - Provocation 12 (London: NESTA, 2009).

${ }^{25}$ Ruth Morrow, “Creative Activism: A Pedagogical and Research Tool,' Enquiry: A Journal for Architectural Research 4, n. I (April 2007), doi:I0.I783 I/enq:arcc.v4il.56.

${ }^{26}$ Paul Carter, Material Thinking: The Theory and Practice of Creative Research (Melbourne, Melbourne University Publishing, 2004), 7.

${ }^{27}$ Mick Abbott and Jacky Bowring, "A Laboratory for Design-Directed Research: Building Design Scholarship and Academic Possibility through Designing," in Applied Collaborations, n.d.
} 
host/promoter research or cultural project. The timing of student projects is constrained by academic timetabling and programming, but their scope can be as wide ranging and provocative as project partners and, crucially, key academics involved feel is appropriate. Below are some reflections on a collection of six week long student projects designed as specific activities or work packages within externally funded research projects lasting between eighteen months and two years. The research and pedagogical context in which those projects were conceived and implemented, and where the author is rooted, is Agency, a now independent research network emerged within the context of the Sheffield School of Architecture (SSOA), concerned with transformative research into practice and education. ${ }^{28}$ As an attempt to challenge the scope and broaden the framing of university-based teaching initiatives with external partners, Agency has been actively working on expanding the field of "live projects" as they are primarily conceptualised at SSoA: a well-established six week learning module, where master's students work in groups "with community clients in real time, with real budgets, on socially-engaged projects." 29 The majority of these projects, faithfully to the module programme, tend to replicate accepted norms of client-professional relationships. Members of Agency have actively attempted to challenge this singular and traditional characterisation of the potential role of architects by initiating and mentoring SSoA live projects concerned with a much wider field of architectural practice. Agency live projects have often been controversial and contested by colleagues, particularly because they challenged the notion of "client," undermining normative understandings of practice. However, the fact that these projects were associated with the work of wider networks, and that they were funded by the EU, has helped to argue for their legitimacy and validity. Agency live projects ranged from the Inconspicuous Yellow Office (IYO), a live project about live projects, ${ }^{30}$ critically reflecting on knowledge production across SSoA live projects and generally perceived as challenging - "Nobody liked us, really"31 - to a series of live projects in France, Northern Ireland and Turkey (associated with EU Culture 2007 project Rhyzom: local cultural production and translocal dissemination ${ }^{32}$ ), to a number of live projects associated with Erasmus-funded lifelong learning networks across EU countries.

One of such Agency-led live projects was associated with the EU funded Rhyzom project and mentored by the author. The client for this live project was the Istanbul-based Rhyzom partner Cultural Agencies, itself a collaborative project and a group seeking 'to develop contemporary models of cultural collaborations and institutional practices', curated by Nikolaus Hirsch, Philipp Misselwitz and the artist collaborative Oda Projesi. In the context of the Istanbul Art Biennial 2009 and of Istanbul's award of European Capital of Culture (2010) Cultural Agencies chose to work outside the "cultural bubble" of the cosmopolitan centre of Istanbul, focusing instead on the politically charged periphery of the city, in the neighbourhoods of Gülensü and Gülsüyü. Students were asked by Cultural

\footnotetext{
${ }^{28}$ Agency Research Centre (AGENCY, June 2010).

29 "About Live Projects," accessed November 6, 2016, http://www.liveprojects.org/about.

${ }^{30}$ Live Project Live Project, "What Is the Live Project Live Project?," last modified October 5, 2006, https://liveproject.wordpress.com/what-is-the-live-project-live-project/.

31 Tatjana Schneider, "Discard an Axiom," in Transdisciplinary Knowledge Production in Architecture and Urbanism: Towards Hybrid Modes of Enquiry, ed. Isabelle Doucet and Nel Janssens (Dordrecht: Springer, 20II), 97-II5.

${ }^{32}$ Cristina Cerulli, Florian Kossak, Doina Petrescu, and Tatjana Schneider, “Agencies of Live Projects by Agency," in Petrescu, Petcou, and Awan, TRANS LOCAL ACT, 287-98.
} 
Agencies to develop an architectural concept to transform the Dukkani, a former shop turned into project base, into a prototype of a new neighbourhood institution. The initial brief and programme of work given to the students by the client were structured around the concepts of "generic institutional programs" as tools for cultural agency: Office, Archive, Communication, Events, Collection and Library. Students worked within this proposed framework suggesting new possible uses, future developments and exit strategies. ${ }^{33}$ From quite early on in the project, however, students assumed a critical stance towards their brief, trying to articulate their unease towards some of the methods and the ethics of their "clients" and negotiating their double commitment to the client, as per professional norms, and to the citizens of the areas in which they were working. As part of the assessment of a module on professional practice students had to write group and individual reflective essays on their live project experiences; in these essays most students highlighted the tensions between different approaches and stances and carrying out their work within the required frameworks (as in professional norms), whilst remaining critical and true to their own beliefs and identified the mediations of these tensions as a key learning from the project.

Another Agency live project mentored by the author and associated with an EU-funded wider program is the Community Economies project ${ }^{34}$. The project dealt explicitly with diverse social and democratic ways of developing community economies within the context of an EU-funded network. Working with their clients Brave New Alps, students co-facilitated an international workshop during which network members shared practices and collectively built the physical infrastructure to turn an industrial building into a usable community facility. The aim of this project was to construct a place that facilitated the creation of 'Community Economies'. The collaborative, transdisciplinary, transnational and inclusive nature of the project meant that the students themselves - along with the forty people from across Europe who joined them in a week-long international workshop, as well as the asylum seekers living on the site of intervention - for the duration of the project were prototyping and enacting a living 'Community Economy'. In this specific instance, the student project was included in the EU Erasmus + bid and it was clearly budgeted for (all student travel and accommodation costs were covered as well as some materials and production costs) and was one of the key contributions of SSoA as a partner. However, by combining the student project with the organisation of a workshop hosted by project partner Brave New Alps and channelling students' work to support the workshop, it was possible to use the workshop to actually build physical infrastructures for a longer-term project, significantly increasing the legacy and impact of both the student project and the workshop. Individual and group reflective essays produced in the context of a complementary module on professional practice showed that students were mostly at ease with working in a context where there professional (technical) skills were both required and somewhat redundant. Students also realised how crucial it was that they were able to translate their work into the language of the funded EU project and map each of their activities on its stringed accounting framework. The concept of multiplier event, built into the EU funding requirement, also made students reflect on the

\footnotetext{
${ }^{33}$ Ibid.

34 "Community Economies," accessed November 6, 2016, https://communityeconomies.wordpress.com/.
} 
value of creating open occasions for creating new values through the convergence of interests.

\section{Taking a Stance and Supporting Others}

Academic project-based research, including student projects, has an incredible potential to support emerging initiatives that would otherwise struggle to find sufficient resources to take off. Designing collaborative pedagogies with civic actors means supporting them by allocating resources and critical input. In the Community Economies project, for instance, the tactical convergence of two smaller and distinctly budgeted activities of a network-building programme literally helped build the infrastructure to support a much longer-term project. Channelling the efforts of teams of academic researchers and students towards supporting initiatives within the city equates to fuelling those initiatives and, for this reason, it is a political gesture.

One instance of such projects is a design studio for MA in Urban Design at SSoA developed in partnership with Sheffield CLT and Studio Polpo. This project was situated outside the SSoA flagship live project module and sought to make collaborative, "live" and practice-based the prevailing mode of learning within the architecture and urban design curriculum, the design studio. The studio set out to explore what can citizens do when the market does not provide a solution; what are the desirable, ethical and just ways of re-appropriating sways of city waiting for "investors"; and how could other ways of making the city that embody more ethical values be prototyped ${ }^{35}$ Community-led development was one framework suggested within which to explore these issues and a focus on one particular type of community-led development, Community Land Trusts (CLTs), was proposed as a lens to reflect on citizen-led initiatives dealing with ownership and stewardship for the benefit of the community.

The project had the declared aim to support the emerging initiative of Sheffield Community Land Trust (Sheffield CLT), a project initiated by Studio Polpo, a Sheffieldbased social enterprise architecture practice that the author co-founded and directs. ${ }^{36}$ Launched a year before the design studio at the Sheffield Housing Festival, in the context of the Homes for Britain national campaign, Sheffield CLT was moving towards an "active" phase aiming to engage with local communities and stakeholders to discuss models, scenarios and potential routes to establish a CLT in Sheffield. The urban design studio was set up to work with Studio Polpo and Sheffield CLT to explore and propose avenues for community-led development in Sheffield City Centre within the wider framework of the Sheffield CLT project.

As one of the two leaders of the design studio and one of the initiators of both the Sheffield CLT project and the not-for-profit architecture practice Studio Polpo, $\mathrm{I}^{37}$ reflected intensely on my role and my position in this project. Was what I was attempting appropriate? Were there any potential conflicts of interest? In some academic contexts alignment and overlapping between studio projects and tutors' "private" practice is seen

\footnotetext{
${ }^{35}$ Cristina Cerulli and Beatrice De Carli, "Project 3 - Re-Appropriating the Post-Industrial Landscape through Community Led Development Introduction Theme," April 2016.

36 "Studio Polpo," accessed November 6, 2016, http://www.studiopolpo.com/.

${ }^{37}$ What follows is a series of reflections, in first person, by the author on aspects of her pedagogical practice in relation to conflux of interest.
} 
as a desirable means to introduce practice "real world" imperatives into architectural education. In the context of SSoA this was seen as a potential problem as well as an important opportunity.

A few years earlier I was prompted to reflect on the commodification of live projects and how they can easily become a trading currency. I had been actively involved in Portland Works, a community-led project that took collective ownership of an industrial heritage asset under threat to run it cooperatively for the benefit of the community. ${ }^{38}$ I had mentored a very successful live project with Portland Works ${ }^{39}$ and, when in conversation with the "client"/partner organisation I co-initiated a second live project two years later, I was unable to mentor the project because I was perceived as "too close to the project." I have spent considerable time since reflecting on what "being too close" might have meant. Was the decision not to allow me to mentor the project motivated by a desire to limit the perceived or implied personal or professional gains that might have resulted from the project? Or was it to allow others to share the limelight associated with this pioneering project that had attracted considerable media attention and was unanimously considered an exemplar? Or was it simply an honest attempt at mitigating potential conflicts of interest? I also reflected on the synergies and interdependencies between my teaching, academic research, practice-based research, and my practice and came to articulate my position in terms of conflux of interests, ${ }^{40}$ where a virtuous, complex mutually beneficial relationship existed for all parties involved and between all the hats that I might be wearing at once.

In the example of the Sheffield CLT urban design live studio, a project that I initiated with others outside the university, as practitioner, benefited from the work of a student project that I designed, as academic. Indirectly, also my practice Studio Polpo benefited from the work of my students because, even as a social enterprise committed to initiating paradigm shifting projects, Studio Polpo would have never been able to allocate comparable resources towards a non-fee-earning project like Sheffield CLT.

Conversely, however, based on reflective portfolios part of the studio assessment, my students found very positive the live aspect of their design studio and valued the fact that their work contributed directly to Sheffield CLT. Some students also pointed out that in a context in which for international students it is increasingly difficult to get work experience within the UK, working with a UK-based practice from within the curriculum also improved their employability.

\footnotetext{
${ }^{38}$ Cristina Cerulli and Julia Udall, Alternative Futures for Portland Works (Sheffield: Antenna Press, 20I I); Cristina Cerulli and Julia Udall, Re-Imagining Portland Works (Sheffield: Antenna Press, 20II); Cristina Cerulli, "Transformative Knowledge Production: The Case of Re-Imagining Portland Works KT Project," ; Cristina Cerulli, "Thresholds of Engagement and Nuanced Approaches in Civic Crowdfunding: Lessons from Portland Works, Sheffield."

39 "Portland Works Live Project," accessed November 6, 2016, http://www.liveprojects.org/20I I/portlandworks/. Live Projects Network, “Decision-Making Tools," accessed November 6, 20I6, http://liveprojectsnetwork.org/project/decision-making-tools-for-portland-works/.

${ }^{40}$ Cristina Cerulli, "Leverage, Alignment and Currencies / Ethics and Methods for Cultural and Educational Institutions Engaging with Processes of Urban Transformation in Contested Areas" (keynote lecture presented at AESOP: Becoming Local: Public Space as an Imaginary of Alternative Urban Futures, Özyeğin University, Istanbul, November 20, 2013).
} 


\section{Conclusion}

Beyond the general aims of the various models of academic project-based research, the specificities of each of these projects with their complex interdependence of aspirations and motives are often determined by a conflux of interests of at least some of the parties involved. This convergence, conflux, of multiple interests, however, is at odds with cultures of professionalism, both in practice and academia and, perhaps, with some legal frameworks associated to them.

Through reflecting on three socially motivated collaborative pedagogical projects and on the ethical issues and value systems associated with them this paper attempted to bring to the foreground an understudied aspect of such projects: the degree of alignment between value systems, motives and objectives and the potential value of the convergence of multiple agendas. The conflux of multiple interests could emerge as a necessary condition for developing successful socially motivated projects; and university-based initiatives can catalyse, fuel, question and help sustain such projects. Converging interests have the potential to create virtuous conditions, amplifying the signal ${ }^{4 \mid}$ of small but significant initiatives, and yet there is no expectation to articulate any conflux of interest, to declare or reveal the interdependencies and multiple benefits accrued by various parties involved in socially-motivated projects. Tactical and opportunistic approaches are often needed to assemble socially-motivated collaborative projects, particularly with regards to creating synergies within a context of resource scarcity.

What if the value of projects was also understood in terms of the number of mutually beneficial relationships that they foster? A new vocabulary is needed to articulate the complexities of interdisciplinary and collaborative projects at the intersection of academic research, professional practice and teaching and learning, to describe the convergence of interests that might underpin and sustain them. Such vocabulary would assist with articulating the value systems underpinning these projects, framing them in a positive way and bypassing the normative focus on competition and its de facto corollary of conflict of interest. This, in turn, will have the potential to create shifts in how the value of professional work is conceptualised.

Similarly to scholarly activist research, ${ }^{42}$ whose rigour needs to be defined in different terms, socially motivated academic project-based research needs to be understood in its own terms and the conflux of multiple interests is one of its key characteristics.

\footnotetext{
${ }^{41}$ Ezio Manzini, 'Enabling Platforms for Creative Communities'.

${ }^{42}$ Diane C. Calleston, Catherine Jordan, and Sarena D. Seifer, "Community-Engaged Scholarship: Is Faculty Work in Communities a True Academic Enterprise?" Academic Medicine 80, n. 4 (2005): 31 7-2I, accessed July 19, 2013. http://journals.Iww.com/academicmedicine/Fulltext/2005/04000/Community_Engaged Scholarship Is Faculty Work in.2.aspx.
} 